\title{
Exigência de Lisina para Aves de Reposição de 0 a 6 Semanas de Idade ${ }^{1}$ \\ José Humberto Vilar da Silva², Luiz Fernando Teixeira Albino ${ }^{3}$, Horacio Santiago Rostagno ${ }^{3}$, Paulo César Gomes ${ }^{3}$, Ricardo Frederico Euclydes ${ }^{3}$
}

\begin{abstract}
RESUMO - Objetivando estimar as exigências de lisina de 0 a 6 semanas e avaliar seus efeitos na fase de produção de ovos, 300 poedeiras leves (PL) Lohmann Selected Leghorn e 300 poedeiras semipesadas (PSP) Isa Brown foram distribuídas em delineamento em blocos ao acaso e alimentadas com ração basal contendo 18,50\% de proteína bruta (PB) e 2.900 kcal de energia metabolizável (EM) suplementada com L-lisina $\mathrm{HCl}$ para os níveis de 0,$75 ; 0,80 ; 0,85 ; 0,90 ;$ e $0,95 \%$ de lisina total nas rações. Na fase de postura, 160 aves de cada linhagem foram alimentadas com ração de produção contendo $16,50 \%$ de PB, 2.900 kcal EM, 2,9\% de $\mathrm{Ca}^{+2}$ e $0,755 \%$ de lisina. As estimativas das exigências de lisina obtidas pela conversão alimentar para a fase de 0 a 6 semanas de idade foram de $0,86 \%$ ou consumo de $254 \mathrm{mg}$ diário para as PL e de $0,87 \%$ ou consumo de $238 \mathrm{mg}$ diário para as PSP. Produção de ovos, consumo de ração e conversão por dúzia de ovos das PSP foram afetados de forma quadrática pelos níveis de lisina da fase de crescimento. Massa de ovos e conversão por massa de ovos das PSP e conversão por massa de ovos das PL foram afetadas de forma linear. Durante a fase de crescimento, as PL apresentaram pior conversão alimentar que as PSP. Durante a fase de produção, as PSP produziram ovos mais leves, mas as conversões por massa e por dúzia de ovos foram superiores às das PL.
\end{abstract}

Palavras-chaves: aminoácido, crescimento, produção e massa de ovos

\section{Requirement of Lysine for Rearing Egg-Type Pullets from 0 to 6 Weeks of Age ${ }^{1}$}

ABSTRACT - The objective of this work were to estimate the requirement of lysine from 0 to 6 weeks and to evaluate the posterior effect on the performance of two egg-type strains. Three hundred egg-white pullets from 0 to 6 week of age and three hundred egg-brown pullets from 0 to 6 week of age were allotted to a randomized block design with five treatments and four replicates. A basal diet with $18.50 \%$ of crude protein (CP) and $2900 \mathrm{kcal}$ metabolizable energy (ME) was supplemented with L-lysine $\mathrm{HCl}$ to obtain $0.75,0.80,0.85$, 0.90 , and $0.95 \%$ of total lysine in the diet. During the laying period all hens received the same diet with $16.5 \mathrm{CP}, 2822 \mathrm{kcal} \mathrm{ME}, 3.81 \%$ $\mathrm{Ca}^{+2}$ and $0.755 \%$ of lysine. The pullets requirement estimates of lysine based on feed: gain was $0.86 \%$ or a daily intake of $254 \mathrm{mg}$ for white-egg and $0.87 \%$ or a daily intake of $238 \mathrm{mg}$ for brown-egg. Egg production, feed intake and egg dozen and egg mass ratio were quadraticly affected. Egg mass and egg mass ratio of brown-egg, and egg mass ratio of white-egg were linearly affected. During the growing phase the white-egg pullets showed worse feed:gain ratio than brown-egg pullets. During the egg production phase the brown-egg pullets showed lighter eggs, but the egg mass and egg dozen ratio were higher than white-egg pullets.

Key Words: amino acid, egg mass and production, growth

\section{Introdução}

Os processos anabólicos em aves de postura em crescimento são altamente dependentes do nível de ingestão de alimentos e de nutrientes disponíveis, para garantir adequada deposição de tecido corporal. $\mathrm{O}$ atendimento das exigências dos aminoácidos para as aves de reposição é considerado etapa crítica na otimização do desempenho subseqüente, sendo afetado por fatores dietéticos, genéticos e ambientais.

Embora exista indicação de melhor desempenho de matrizes pesadas sujeitas à restrição de lisina durante o crescimento (COUCH et al., 1967), os resultados obtidos com poedeiras comerciais na fase de 0 a 6 semanas de idade têm contrariado esta observação, em virtude do aumento do canibalismo (LEE et al., 1971) e da queda permanente da produção e peso dos ovos (CONNOR et al., 1977).

Essa discrepância parece sugerir que matrizes pesadas não são bons modelos para a definição do melhor método de restrição alimentar para as aves de postura comercial. Existem diferenças marcantes na taxa de crescimento e produção de ovos entre ambas (HOCKING et al., 1987), que justificam a alimentação ad libitum até o ponto de postura das poedeiras comerciais e restrição alimentar para as matrizes

\footnotetext{
1 Parte da tese de Doutorado do primeiro autor. Bolsista do convênio PICDT-Capes/UFPB

${ }^{2}$ Presente endereço: Colégio Agrícola A. Vidal de Negreiros/DAP/CFT/UFPB/Bananeiras/PB/Brasil. CEP. 58.220-000. E.mail: jvilar@cft.ufpb.br

3 Professor do Departamento de Zootecnia da UFV. Viçosa-MG, Brasil. CEP. 36.570-000.
} 
(WADDINGTON e HOCKING, 1993), mesmo porque as poedeiras comerciais apresentam notável capacidade de ajustar o consumo de ração às exigências, sem afetar a taxa de postura (FLOCK, 1998), o que não é possível com matrizes pesadas.

WELLS (1980), entretanto, postulou que a composição do corpo de poedeiras em crescimento tem mais influência no ótimo desempenho de postura que o peso corporal. Essa informação foi confirmada posteriormente por KWAKKEL et al. (1991). Essa afirmação também sugere que os ganhos genéticos nas poedeiras comerciais nos últimos 25 anos, com redução do peso corporal, do consumo de ração e da conversão alimentar e aumento da massa de ovos produzida (SHALEV, 1995; FLOCK, 1998) requerem estudos permanentes de atualização das exigências nutricionais para que a máxima taxa potencial de produção seja alcançada.

ROSTAGNO et al. (1983) sugeriram 0,902\% de lisina na ração de poedeiras de 0 a 6 semanas de idade, enquanto que o NATIONAL RESEARCH COUNCIL - NRC (1994) dividiu a recomendação em $0,85 \%$ para as aves leves e $0,82 \%$ para as semipesadas. Entretanto, essas exigências foram estabelecidas há bastante tempo, empregando alimentos e aves com potencial genético muito diferentes das linhagens de postura moderna.

Os objetivos deste trabalho foram atualizar as exigências em lisina de poedeiras leves e semipesadas de 0 a 6 semanas de idade e avaliar o efeito desses níveis sobre o rendimento produtivo das aves.

\section{Material e Métodos}

O experimento foi realizado no Setor de Avicultura do Departamento de Zootecnia da Universidade Federal de Viçosa, no período de 05 de junho de 1997 a 11 de março de 1998.

\section{Fase de crescimento}

Um total de 600 aves, 300 poedeiras leves (PL) Lohmann Selected Leghorn e 300 poedeiras semipesadas (PSP) ISA-Brown de 0 a 6 semanas de idade, identificadas por tratamento, foram pesadas e alojadas em boxes de 1 × $2 \mathrm{~m}$, contendo cama de maravalha, uma lâmpada de infravermelho para aquecimento das aves, um comedouro tubular e um bebedouro pendular. $\mathrm{O}$ galpão onde o experimento foi realizado apresentava orientação Norte-Sul, telhado em duas águas com lanternin, pé direito de $4 \mathrm{~m}$ e duas caixas d'água instaladas no seu interior, com uma fileira dupla de boxes, separada das fileiras laterais por dois corredores, cada um com $1 \mathrm{~m}$ de largura.

Aos 10 dias de idade, as aves foram submetidas à debicagem para prevenção de canibalismo e a um esquema básico de vacinação e controle das principais enfermidades em aves de postura.

Uma ração basal deficiente em lisina com 18,50\% de proteína bruta (NRC, 1994) e $2.900 \mathrm{kcal}$ de EM/kg (ROSTAGNO et al., 1983) foi suplementada com 0,000; 0,064; 0,128; 0,192; e 0,256 de L-lisina HCl, de forma a proporcionar cinco níveis de lisina nas rações de 0,$75 ; 0,80 ; 0,85 ; 0,90$; e $0,95 \%$ (Tabela 1 ). Inicialmente, as duas misturas das extremidades foram preparadas e seguidas por uma série de diluições para se obterem as rações com níveis intermediários.

O sorgo de baixo tanino e o glúten de milho foram incluídos em substituição ao milho e farelo de soja, para reduzir o conteúdo de lisina da ração basal e por serem, respectivamente, boas fontes de energia e proteína em rações de aves.

Os parâmetros avaliados foram consumo de ração e de lisina, ganho de peso e conversão alimentar.

Concluída a fase de 0 a 6 semanas, as aves foram transferidas para o galpão de recria, onde permaneceram até as 22 semanas, sendo criadas de forma convencional e alimentadas com rações ad libitum, balanceadas para todos os nutrientes.

\section{Fase de postura}

O galpão de postura, de $60 \times 9 \mathrm{~m}$, com telas nas laterais à prova de pássaro, coberto com telhas de barro em duas águas, apresentava dois conjuntos de quatro fileiras de gaiolas, separadas por um corredor central de $2 \mathrm{~m}$, sendo utilizadas apenas duas fileiras centrais de cada conjunto. Durante a fase de produção, o fotoperíodo utilizado foi de 16 horas por dia.

Às 22 semanas de idade, 160 frangas Lohmann LSL e 160 Isa Brown foram pesadas e transferidas do piso para as gaiolas de produção. As aves foram alojadas ao acaso em quatro repetições por tratamento, cada uma com oito aves. A água foi distribuída em bebedouros de água corrente de alumínio, tipo V, localizados acima dos comedouros.

Uma ração de produção (Tabela 1) foi fornecida ad libitum a todas as aves, com a finalidade de permitir a avaliação do efeito residual dos níveis de lisina do período de 0 a 6 semanas, sendo formulada para atender ou exceder as exigências das aves em energia metabolizável, proteína e lisina, conforme ROSTAGNO et al. (1996), e demais nutrientes incluídos, de acordo com o NRC (1994). 
Rev. bras. zootec.

Tabela 1 - Composições da ração basal de 0 a 6 semanas e da ração de produção 1

Table 1 - Compositions of the basal diet from 0 to 6 weeks and production diet

\begin{tabular}{|c|c|c|}
\hline $\begin{array}{l}\text { Componentes } \\
\text { Components } \\
\end{array}$ & $\begin{array}{l}\text { Inicial }^{2} \\
\text { Starter }\end{array}$ & $\begin{array}{l}\text { Produção de ovo } \\
\text { Egg production }\end{array}$ \\
\hline Milho, $8,07 \% \mathrm{~PB}^{3}$ (Corn) & 32,000 & 66,307 \\
\hline Farelo de soja, $45,79 \% \mathrm{~PB}^{3}$ (Soybean meal) & 18,580 & 19,812 \\
\hline Sorgo baixo tanino, $8,82 \% \mathrm{~PB}^{3}$ (Sorghum, low tanin) & 35,000 & - \\
\hline Glúten de milho, $60,90 \% \mathrm{~PB}^{3}$ (Corn gluten meal) & 6,925 & 2,795 \\
\hline Amido (Starch) & 0,640 & - \\
\hline Calcário(Limestone) & 1,138 & 8,801 \\
\hline Fosfato bicálcico (Dicalcium phosphate) & 1,634 & 1,629 \\
\hline DL-metionina (DL-methionine) & - & 0,071 \\
\hline Premix mineral ${ }^{4}$ (Mineral premix) & 0,050 & 0,050 \\
\hline Premix vitamínico ${ }^{5}$ (Vitamin premix) & 0,100 & 0,100 \\
\hline Cloreto de colina (Choline chloride) & 0,020 & 0,020 \\
\hline Bacitracina de zinco (Zinc bacitracin) & 0,025 & 0,010 \\
\hline Sal (Salt) & 0,302 & 0,396 \\
\hline BHT & 0,010 & 0,010 \\
\hline Anticoccidiano (Coccidiostatic) & 0,050 & - \\
\hline Caulin & 3,526 & - \\
\hline \multicolumn{3}{|l|}{$\begin{array}{l}\text { Composição calculada } \\
\text { Calculated composition }\end{array}$} \\
\hline Proteína bruta (Crude protein), $\%$ & 18,500 & 16,500 \\
\hline $\mathrm{EM}(M E), \mathrm{kcal} / \mathrm{kg}$ & 2.900 & 2.822 \\
\hline Cálcio (Calcium), \% & 0,900 & 3,810 \\
\hline Fósforo disponível (Available phosphorus), \% & 0,401 & 0,400 \\
\hline Lisina (Lysine), \% & 0,750 & 0,755 \\
\hline Metionina + Cistina $(M e t+C y s), \%$ & 0,628 & 0,647 \\
\hline Metionina (Methionine), \% & 0,340 & 0,361 \\
\hline Treonina (Threonine), \% & 0,696 & 0,640 \\
\hline Triptofano (Triptophan), \% & 0,201 & 0,198 \\
\hline Sódio (Sodium), \% & 0,150 & 0,190 \\
\hline
\end{tabular}

1 Composição calculada conforme ROSTAGNO et al. (1983), e NATIONAL RESEARCH COUNCIL - NRC (1994). (Composition calculated accoeding to ROSTAGNO et al., 1983 and NATIONAL RESEARCHCOUNCIL - NRC, 1994).

2 Ração basal suplementada com L-Lis HCL - 78,4\% de Lisina e 100 \% digestível (Basal diet supplemented with L-Lys HCI - $78.4 \%$ of lysine and $100 \%$ digestible).

3 Análises realizadas no Laboratório de Nutrição Animal da UFV (Analysis were carried out at the Animal Nutrition Laboratory of UFV).

4 Premix mineral - Fase de crescimento (Growth phase): Composição/kg: $65 \mathrm{~g} \mathrm{Fe;} \mathrm{0,5} \mathrm{g} \mathrm{l;} 55 \mathrm{~g} \mathrm{Zn;} 70 \mathrm{~g} \mathrm{Mn;0,15} \mathrm{g} \mathrm{Se;} 10$ g Cu e $500 \mathrm{~g}$ excipiente Q.S.P. Fase de produção (Production phase): Composição/kg: $100 \mathrm{~g} \mathrm{Fe;} 2 \mathrm{~g} \mathrm{I} ; 100 \mathrm{~g} \mathrm{Zn;} 160 \mathrm{~g}$ $\mathrm{Mn} ; 20 \mathrm{~g} \mathrm{Co} ; 20 \mathrm{~g} \mathrm{Cu}$; e $1000 \mathrm{~g}$ excipiente Q.S.P.

5 Premix vitamínico - Fase de crescimento (Growth phase): Composição/kg: Vit. A - 15.000 .000 U.I.; D - 1.500.000 U.I.; Vit. E - 15.000 UI; Vit. $K_{3}$ - 3 g; Vit. $B_{1}$ - 2,0 g; Vit. $B_{2}$ - 4,0 g; Vit. B - 3,0 g; Vit. B 12 - 0,015 g; Ácido nicotínico (Nicotinic acid) - $25 \mathrm{~g}$; Ácido fólico (Folic acid) - 1,0 g; Ácido pantotênico (Pantotenic acid) - $10 \mathrm{~g}$; Biotina (Biotin)- $70 \mathrm{mg}$; Selênio (Selenium) - $100 \mathrm{mg} ; 10 \mathrm{~g}$ antioxidante BHT e excipiente Q.S.P. (1.000 g). Fase de produção (Production phase): Composição/kg: Vit. A - 12.000.000 U.I; Vit. $D_{3} 3.600 .000$ U.I.; Vit. E - 35.000 Ul; Vit. $K_{3}-3$ g; Vit. $B_{1}$ - 2,5 g; Vit. $B_{2}$ - 8,0 g; Vit. $B_{6}$ $5,0 \mathrm{~g}$; Vit. $\mathrm{B}_{12}-0,020 \mathrm{~g} ; 40 \mathrm{~g}$ Ácido nicotínico (Nicotinic acid); $1,5 \mathrm{~g}$ Ácido fólico (Folic acid); $12 \mathrm{~g}$ ácido pantotênico (Pantotenic acid); Biotina (Biotin) - 200 mg; Selênio (Selenium) - 150 mg; e excipiente Q.S.P. (100 g).

Os dados de postura foram obtidos em quatro períodos de 28 dias (26 a 42 semanas). No início e final de cada período, as aves e rações foram pesadas. A produção de ovos foi anotada diariamente e os ovos produzidos nos últimos 5 dias de cada período, pesados nos dias posteriores às coletas. As variáveis estudadas foram produção de ovos, consumo de ração, peso e massa de ovos e conversões por massa e dúzia de ovos.

$\mathrm{O}$ experimento foi realizado em um delineamento em blocos casualizados em esquema fatorial $5 \times 2$ (cinco níveis de lisina e duas linhagens de postura comercial), com quatro repetições de quinze aves de 0 a 6 semana, e oito aves durante o período de produção, empregando o seguinte modelo estatístico:

$$
\mathrm{Y}_{\mathrm{ijkl}}=\mu+\mathrm{B}_{1}+\mathrm{N}_{\mathrm{i}}+\mathrm{L}_{\mathrm{j}}+\mathrm{N}_{\mathrm{i}} \mathrm{L}_{\mathrm{j}}+\mathrm{e}_{\mathrm{ijkl}}
$$

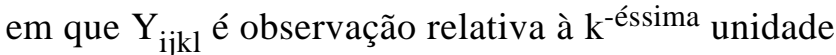

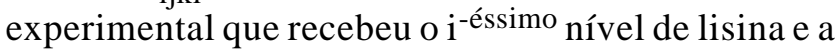

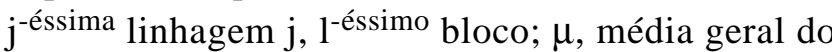
experimento; $\mathrm{B}_{1}$, efeito do l-éssimo bloco, sendo $1=1$, $\ldots 4 ; \mathrm{N}_{\mathrm{i}}$, efeito do $\mathrm{i}^{\text {éssimo }}$ nível de lisina, sendo $\mathrm{i}=0,75$; 0,$80 ; 0,85 ; 0,90 ;$ e $0,95 \% ; L_{j}$, efeito da $j^{\text {-éssima linhagem, }}$ 
sendo $\mathrm{j}=1$ e $2 ; \mathrm{N}_{\mathrm{i}}{ }^{*} \mathrm{~L}_{\mathrm{j}}$, efeito de interação dos níveis de lisina i e a linhagem $\mathrm{j}$; $\mathrm{e}_{\mathrm{ijk}}$, erro experimental, sendo o erro $\operatorname{NID}\left(0, \sigma^{2}\right)$.

As somas de quadrados dos tratamentos foram desdobradas nos efeitos lineares, quadráticos, cúbicos e quárticos, conforme procedimento do SAEG (UNIVERSIDADE FEDERAL DE VIÇOSA - UFV, 1982). As exigências de lisina de cada linhagem foram estimadas pelo modelo de regressão quadrático, considerando o coeficiente de determinação $\left(\mathrm{R}^{2}\right)$ e a interpretação biológica dos parâmetros.

Os valores estimados das exigências de lisina foram empregados para obter a relação lisina com os valores calculados de aminoácidos importantes na ração de poedeiras em crescimento e comparados com a relação obtida da recomendação de aminoácido total do NRC (1994).

\section{Consumo diário de lisina total e digestível}

As quantidades diárias de lisina total a serem fornecidas às aves foram obtidas considerando as estimativas percentuais das exigências de lisina como variável independente das equações de regressões lineares dos consumos de lisina total, em função da concentração de lisina total na ração. Em seguida, os valores calculados de lisina total foram multiplicados pelo coeficiente de digestibilidade verdadeira de lisina de 89\% (ROSTAGNO, et al., 1996), para obtenção da quantidade diária de lisina digestível.

\section{Resultados e Discussão}

\section{Temperatura ambiente}

Durante a fase de crescimento, as temperaturas noturnas tiveram média de $13^{\circ} \mathrm{C}$, o que, provavelmente, não representa a temperatura efetiva, alterada pelas aves por meio de aglomeração, localização em pontos quentes e pouco ventilados, imobilidade, estímulo ao crescimento de penas e aumento do consumo de ração. $\mathrm{Na}$ fase de postura, as médias das temperaturas diurnas ficaram acima de $30^{\circ} \mathrm{C}$ de 30 a 42 semanas de idade, ultrapassando o limite de $27^{\circ} \mathrm{C}$, que, segundo CHARLES (1992), começa a afetar o consumo de poedeiras.

\section{Desempenho na fase de crescimento}

$\mathrm{O}$ ganho de peso das aves leves não foi afetado pelos níveis de lisina das rações. Ao contrário, CONNOR et al. (1977) observaram efeito significativo dos níveis de lisina, variando de 0,64 a 1,04\%, na fase de 0 a 6 semanas, sobre o ganho de peso de aves leves. Entretanto, o ganho de peso das aves semipesadas foi afetado de forma quadrática $(\mathrm{P}<0,01)$ e o máximo ganho foi obtido com o nível de $0,86 \%$ de lisina na ração (Tabela 2).

Houve efeito quadrático $(\mathrm{P}<0,05)$ para o consumo de ração das aves leves, mas nenhum efeito significativo foi observado para o consumo das aves semipesadas, com o aumento dos níveis de lisina das rações (Tabela 2).

Tabela 2 - Ganho de peso (GP), consumo de ração (CR), conversão alimentar (CA) e consumo de lisina (CL) de poedeiras leves (PL) e semipesadas (PSP) no período de 0 a 6 semanas de idade

Table 2 - Average weight gain (WG), feed intake (FI), feed: gain ratio (F/G) and lysine intake (LI) of light layer hens (LL) and heavily layer hens $(H L)$ from 0 to 6 weeks of age

\begin{tabular}{|c|c|c|c|c|c|c|c|c|}
\hline \multirow{2}{*}{$\begin{array}{l}\% \text { Lisina } \\
\% \text { Lysine }\end{array}$} & \multirow{2}{*}{\multicolumn{2}{|c|}{$\begin{array}{l}\text { GP (g/ave/d) } \\
W G(g / h e n / d)\end{array}$}} & \multirow{2}{*}{\multicolumn{2}{|c|}{$\begin{array}{c}\text { CR (g/ave/d) } \\
F I(\text { g/hen/d) }\end{array}$}} & \multirow{2}{*}{\multicolumn{2}{|c|}{$\begin{array}{l}\mathrm{CA}(\mathrm{kg} / \mathrm{kg}) \\
F / G(k g / \mathrm{kg})\end{array}$}} & \multirow{2}{*}{\multicolumn{2}{|c|}{$\begin{array}{c}\text { CL (mg/ave/d) } \\
L I(m g / h e n / d)\end{array}$}} \\
\hline & & & & & & & & \\
\hline & $\mathrm{PL}^{2}$ & $\mathrm{PSP}^{2}$ & $\mathrm{PL}^{2}$ & PSP & $\mathrm{PL}^{2}$ & $\mathrm{PSP}^{2}$ & $\mathrm{PL}^{1}$ & $\mathrm{PSP}^{1}$ \\
\hline & $L L$ & $H L$ & $L L$ & $H L$ & $L L$ & $H L$ & $L L$ & $H L$ \\
\hline 0,75 & 8,83 & 8,33 & 31,11 & 28,09 & 3,52 & 3,37 & 233,30 & 210,65 \\
\hline 0,80 & 8,70 & 8,77 & 28,91 & 27,87 & 3,32 & 3,18 & 231,29 & 222,95 \\
\hline 0,85 & 8,88 & 8,70 & 29,48 & 26,79 & 3,32 & 3,08 & 250,55 & 227,68 \\
\hline 0,90 & 8,72 & 8,55 & 28,99 & 27,28 & 3,33 & 3,19 & 260,95 & 245,50 \\
\hline 0,95 & 8,61 & 8,58 & 29,51 & 27,44 & 3,43 & 3,20 & 280,31 & 260,68 \\
\hline Média & $8,75^{\mathrm{a}}$ & $8,58^{\mathrm{b}}$ & $29,60^{\mathrm{a}}$ & $27,49^{\mathrm{b}}$ & $3,38^{a}$ & $3,20^{\mathrm{b}}$ & $251,28^{a}$ & $233,49^{b}$ \\
\hline \multicolumn{9}{|l|}{ Average } \\
\hline $\begin{array}{l}\text { Probabilidade } \\
\text { Probability }\end{array}$ & $\mathrm{ns}$ & $* * *$ & $* *$ & $\mathrm{~ns}$ & $* * *$ & $* * *$ & $* * *$ & $* * *$ \\
\hline CV\% & \multicolumn{2}{|c|}{1,787} & \multicolumn{2}{|c|}{3,073} & \multicolumn{2}{|c|}{3,303} & \multicolumn{2}{|c|}{3,199} \\
\hline \multicolumn{9}{|c|}{ 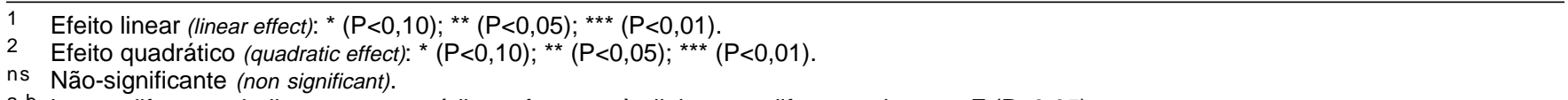 } \\
\hline $\begin{array}{l}\mathrm{a}, \mathrm{b} \text { Letras diferen } \\
\text { are different by }\end{array}$ & ! & & & & & & & \\
\hline
\end{tabular}


Este resultado discorda do obtido por CONNOR et al. (1977), que, observaram menor consumo. Entretanto, a discrepância nos resultados repousa sobre as diferentes condições climáticas entre os dois experimentos. No presente estudo, as aves foram mantidas em condições naturais, enquanto no estudo daqueles autores as aves foram mantidas em condições de ambiente controlado.

Este achado é consistente com os dados de Waldroup e Harms (1962), citados por DOUGLAS e HARMS (1982), que, ao submeterem frangas de reposição à deficiência severa de proteína (10\%) durante o outono (frio), observaram maior consumo que a ração contendo nível normal de proteína (21\%). Da mesma forma, KLAIN et al. (1962) induziram o aumento do consumo de ração imbalanceada pela exposição de ratos ao frio $\left(7^{\circ} \mathrm{C}\right)$, restabelecendo a taxa de crescimento sem evidenciar efeito de lesão patológica.

É provável que o aumento do consumo das rações imbalaceadas aumentou a produção de calor corporal devido ao rápido catabolismo protéico e impediu a mortalidade das aves por estresse pelo frio. Esta observação concorda com a conclusão de KWAKKEL et al. (1991), que consideraram o catabolismo protéico uma forma de evitar a alta mortalidade entre aves de reposição durante o estresse pelo frio.

O aumento do consumo de ração quando as aves são mantidas em temperaturas inferiores a $21^{\circ} \mathrm{C}$ já está bem documentado na literatura (HOWLIDER e ROSE, 1987; DESCHUTTER e LEESON, 1988; e SAKOMURA et al., 1993), como também o rápido aumento da termogênese pelo catabolismo protéico (MORRIS et al., 1999).

A explicação para a falta de efeito significativo do consumo das aves semipesadas pode estar relacionado à maior resistência ao frio. $\mathrm{O}$ rápido crescimento de penas dessa linhagem deve ser a provável explicação, mas nenhuma referência reforçando esta hipótese foi encontrada na literatura.

Evidências têm mostrado o importante papel do empenamento na termoregulação, contribuindo para o controle da perda excessiva de calor do corpo da ave em condições de estresse pelo frio (DESCHUTTER e LEESON, 1986; ZOLLITSCH et al., 1996; e FURLAN e MACARI, 1998).

As conversões alimentares das aves leves $(\mathrm{P}<0,01)$ e semipesadas $(\mathrm{P}<0,10)$ mostraram efeitos quadráticos, e as estimativas das exigências de lisina foram, respectivamente, de 0,86 e $0,87 \%$ (Tabela $2 \mathrm{e}$ Figura 1). A exigência de lisina estimada para as aves leves foi $1,15 \%$ inferior à das semipesadas. Ao contrário, o NRC (1994), sugeriu valor 5,9\% inferior para as semipesadas em relação às leves.

A exigência de lisina das aves leves foi superior à recomendada por CHUNG et al. (1973), de 0,82\%, e próxima à sugestão do NRC (1994), de 0,85\%. Entretanto, a estimativa de $0,87 \%$ de lisina na ração das aves semipesadas foi superior ao valor recomendado pelo NRC (1994) de 0,80\%. A recomendação geral de lisina apresentada por ROSTAGNO et al. (1983), de 0,90\%, foi superior às estimativas obtidas no presente trabalho para ambas as linhagens.

O valor recomendado no MANUAL DA LINHAGEM LOHMANN (1997), de 1,00, e no MANUAL DA LINHAGEM ISA BROWN (1996), de $1,16 \%$, até a terceira semana, e de $0,98 \%$, até a sexta semana, são maiores que os obtidos neste trabalho e os obtidos por CONNOR et al. (1977). Estas discrepâncias podem estar relacionadas às diferenças na higiene das instalações onde estas estimativas foram obtidas.

Segundo KLASING e BARNES (1988), as exigências de lisina obtidas em condições de ambiente limpo e baixo estresse não subestimam, mas, provavelmente, superestimam as necessidades das aves criadas em condições comerciais, nas quais as aves estão sujeitas à ação de vários estressores ambientais.

$\mathrm{O}$ fato de nenhum aminoácido estar presente na ração basal em concentração suficiente para manifestar o efeito deletério da toxidez e antagonismo, e a depressão na conversão alimentar pela deficiência

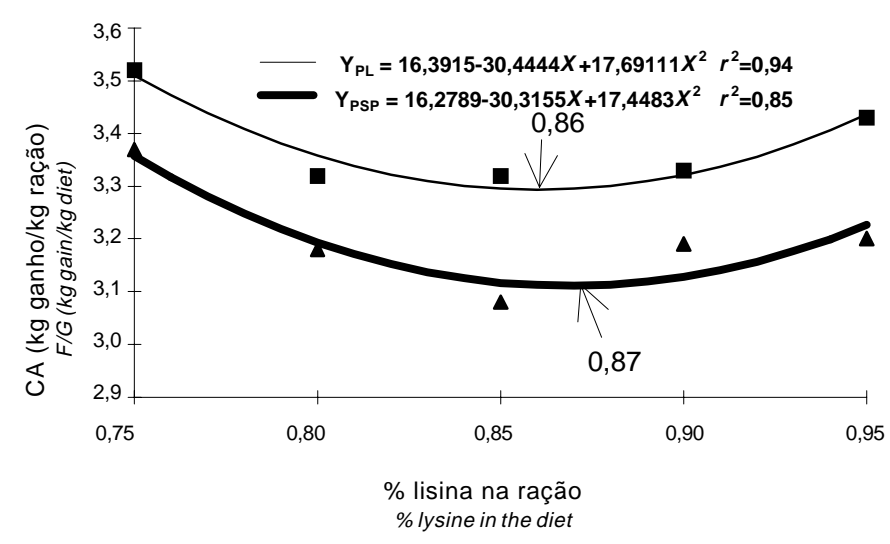

Figura 1 - Conversão alimentar (kg de ração/kg de ganho de peso) das aves em função do nível de lisina na ração.

Figure 1 - Feed:gain ratio (kg diet/kg weight gain) of laying hens in function of dietary lysine level. 
ou excesso de lisina ter sido aliviada pela adição de lisina na forma pura, até o limite em que as relações lisina, proteína e energia foram ótimas, sugere claramente o imbalanço como a principal causa envolvida.

Este resultado não foi inesperado, em virtude de a ração basal ter sido formulada com nível adequado de proteína, exigindo ótimo balanço de aminoácidos para promover o crescimento das aves, o que não foi possível obter nos níveis extremos de lisina. Esta hipótese é consistente com as observadas por outros autores (FISHER et al., 1960; MORRIS et al., 1987; ROBBINS, 1987; ABEBE e MORRIS, e RANGELLUGO et al., 1994).

As estimativas obtidas no presente trabalho mostram a necessidade de atualização da recomendação de lisina e, provavelmente, de outros nutrientes do NRC (1994), especialmente, para as aves semipesadas.

A razão dessa discrepância está, provavelmente, relacionada à falta de dados recentes sobre as exigências dessas aves. Segundo o NRC (1994), as estimativas disponíveis para as aves semipesadas de muitos nutrientes estão desatualizadas. As linhagens de postura modernas têm diferentes padrões de consumo daquelas criadas no passado e são mais eficientes na utilização dos nutrientes consumidos, exigindo, quantitativamente, menos alimentos que as poedeiras de antigamente.

O consumo de lisina cresceu de forma linear $(\mathrm{P}<0,05)$ (Tabela 2 e Figura 2), evidentemente impulsionado pelos aumentos da concentração de lisina e do consumo das rações. Fenômeno semelhante foi reportado em frangos de corte por CONHALATO (1998).

Devido à variação individual no consumo de ração, as exigências para lisina em valores percentuais foram introduzidas como variáveis independentes dos modelos de regressão linear do consumo de lisina em função da concentração de lisina na ração, obtendo-se o consumo diário de lisina de $254 \mathrm{mg} /$ ave/dia, e de $238 \mathrm{mg} /$ ave/dia de lisina total, respectivamente, para as poedeiras leves e semipesadas.

Considerando a digestibilidade de $89 \%$ de lisina (ROSTAGNO et al., 1996), as exigências de lisina digestível foram estimadas em $0,765 \%$ ou $226 \mathrm{mg}$ /ave/dia para as poedeiras leves e de $0,774 \%$ ou $212 \mathrm{mg} / \mathrm{ave} / \mathrm{dia}$ para as semipesadas.

Segundo GOUS et al. (1987), a apresentação das estimativas em termos quantitativos é a melhor forma de expressar as exigências para um nutriente, em virtude de as aves necessitarem de nutrientes de forma quantitativa, e não em porcentagem.
Durante a fase de crescimento, não foi registrado caso de canibalismo. Este resultado deve estar relacionado à deficiência marginal de lisina nas rações, à baixa densidade de criação e amplos espaços de comedouro e bebedouro disponíveis por ave.

Dados de LEE et al. (1971) parecem apoiar esta conclusão, ao constatarem sério canibalismo, durante a fase de crescimento, em duas linhagens leves severamente deficientes em lisina $(0,3 \%)$. KWAKKEL et al. (1991) também observaram bicagem intensa de penas, com ocorrência de canibalismo, em aves severamente deficientes em lisina na fase inicial.

Houve apenas uma morte nos tratamentos com 0,$75 ; 0,85$; e $0,90 \%$ de lisina na ração, que, provavelmente, não esteve diretamente associada aos tratamentos.

Com base nas exigências das aves pela conversão alimentar, foram definidas as relações de lisina e alguns aminoácidos importantes na alimentação de poedeiras (Tabela 3). As relações de lisina e metionina + cistina e lisina e treonina foram semelhantes, mas as relações lisina e metionina e lisina e triptofano foram maiores que as do NRC (1994).

$\mathrm{O}$ percentual adequado de lisina em relação à proteína calculada da ração foi de $4,65 \%$ para as aves leves e $4,70 \%$ para as semipesadas. Estes valores foram próximos ao descrito por SCOTT (1988) para as aves leves de 0 a 2 semanas de idade, $4,70 \%$, e

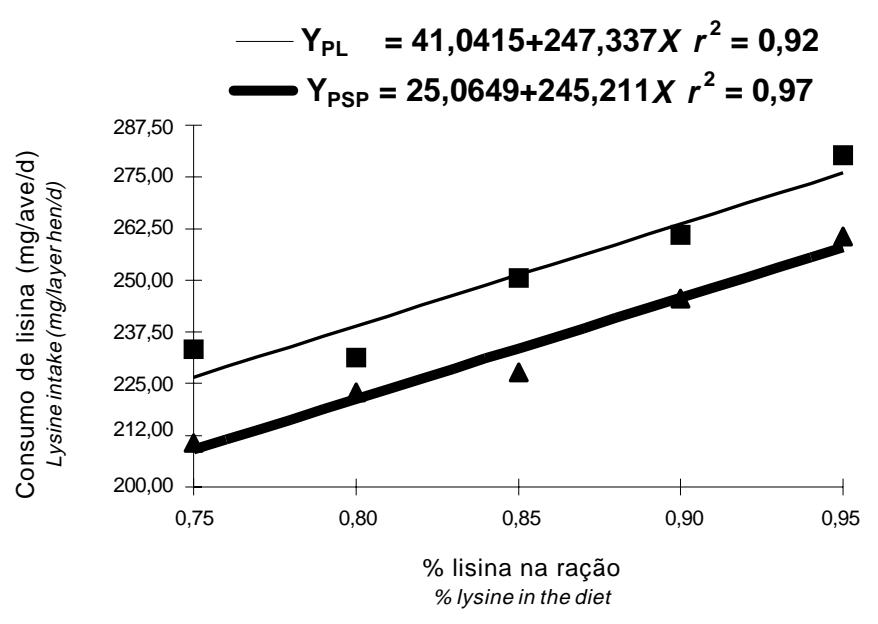

Figura 2 - Consumo de lisina das poedeiras em função do nível de lisina na ração.

Figure 2 - Lysine intake of laying hens in function of dietary lysine level. 
Rev. bras. zootec.

Tabela 3 - Balanço de aminoácidos em rações de poedeiras comerciais, expresso como percentagem de lisina total

Table 3 - Balance of amino acids in commercial laying hens diet, express as percentage of total lysine

\begin{tabular}{|c|c|c|c|c|}
\hline \multirow[t]{2}{*}{$\begin{array}{l}\text { Aminoácidos } \\
\text { Amino acids }\end{array}$} & \multicolumn{2}{|c|}{$\begin{array}{l}\text { Poedeiras } \\
\text { leves } \\
\text { Brown-egg } \\
\text { layer hens }\end{array}$} & \multicolumn{2}{|c|}{$\begin{array}{c}\text { Poedeiras } \\
\text { semipesadas } \\
\text { Brown-egg } \\
\text { layer hens }\end{array}$} \\
\hline & $\begin{array}{c}\text { UFV } \\
\text { (1999) }\end{array}$ & $\begin{array}{l}\text { NRC } \\
(1994)\end{array}$ & $\begin{array}{l}\text { UFV } \\
\text { (1999) }\end{array}$ & $\begin{array}{c}\text { NRC } \\
\text { (1994) }\end{array}$ \\
\hline $\begin{array}{l}\text { Lisina } \\
\text { Lysine }\end{array}$ & 100 & 100 & 100 & 100 \\
\hline $\begin{array}{l}\text { Metionina } \\
\text { Methionine }\end{array}$ & 40 & 35 & 39 & 35 \\
\hline $\begin{array}{l}\text { Met }+ \text { Cis } \\
M e t+C y s\end{array}$ & 73 & 73 & 72 & 74 \\
\hline $\begin{array}{l}\text { Treonina } \\
\text { Threonine }\end{array}$ & 81 & 80 & 80 & 80 \\
\hline $\begin{array}{l}\text { Triptofano } \\
\text { Triptophan } \\
\text { Relacão Lis:PB }\end{array}$ & 23 & 20 & 23 & 20 \\
\hline $\begin{array}{l}\text { Lys:CP ratio } \\
\text { Relação Lis:EM }\end{array}$ & 4,65 & 4,72 & 4,70 & 4,70 \\
\hline Lys:ME ratio & 0,30 & 0,30 & 0,30 & 0,28 \\
\hline
\end{tabular}

pelo NRC (1994).

A relação lisina e energia obtida para as aves leves foi similar, mas para as semipesadas foi superior as do NRC (1994). A semelhança na relação lisina e energia das aves leves, e a diferença em relação às aves semipesadas reforça a necessidade de reavaliação dos valores recomendados para as aves semipesadas.

\section{Fase de postura}

Diversos autores têm afirmado previamente que a composição do corpo é fator mais importante que o peso corporal como indicador do preparo do organismo da poedeira para a produção de ovos (WELLS, 1980, JONHSON et al., 1985, SUMMERS et al., 1987).

A escolha das aves para similar peso corporal não evitou pequenas alterações na idade a $50 \%$ de produção. As aves leves submetidas à ração com $0,75 \%$ de lisina atrasaram 1 dia para atingir $50 \%$ de produção, em relação àquelas que receberam rações com 0,80 e $0,85 \%$ de lisina. Enquanto que a alimentação das aves semipesadas com os níveis de 0,75 e $0,95 \%$ de lisina atrasou dois dias em relação aos tratamentos de 0,$80 ; 0,85$; e $0,90 \%$. As aves leves alcançaram 50\% de produção aos 160 dias e as semipesadas, aos 164 dias de idade.

Existiram efeitos quadráticos para a produção de ovos $(\mathrm{P}<0,10)$, consumo de ração $(\mathrm{P}<0,10)$ e conversão alimentar por dúzia de ovos $(\mathrm{P}<0,05)$ com estimativas de, respectivamente, 0,$90 ; 0,86$; e $0,89 \%$ de lisina na ração, que resultaram no valor médio de $0,88 \%$, levemente superior a $0,87 \%$, obtido pela conversão alimentar durante a fase de crescimento.

O efeito quadrático sobre a produção de ovos das aves semipesadas não apóia a hipótese do ganho compensatório de KWAKKEL et al. (1991), nas fases subseqüentes à fase inicial, com as aves sendo alimentadas ad libitum com rações contendo níveis adequados de lisina, mas é consistente com os resultados de CONNOR et al. (1977), que verificaram efeito irreversível da deficiência de lisina de 0 a 6 semanas sobre o desempenho das aves.

O peso dos ovos não foi afetado pelos níveis de lisina no período de criação, provavelmente, pelas aves terem sido escolhidas para similar peso corporal. Ao contrário, CONNOR et al. (1977) observaram redução significativa no peso do ovo das aves submetidas à ração com $0,64 \%$ de lisina de 0 a 6 semanas de idade, em comparação com a ração contendo 1,04\%. Ao contrário, KWAKKEL et al. (1991) observaram que o nível mais deficiente em lisina na ração aumentou o peso dos ovos.

A conversão alimentar por massa de ovos de ambas as linhagens caiu linearmente $(\mathrm{P}<0,05)$, com o aumento dos níveis de lisina da ração (Figura 3). A provável explicação para esse resultado foi o aumento da massa de ovos produzida com o aumento

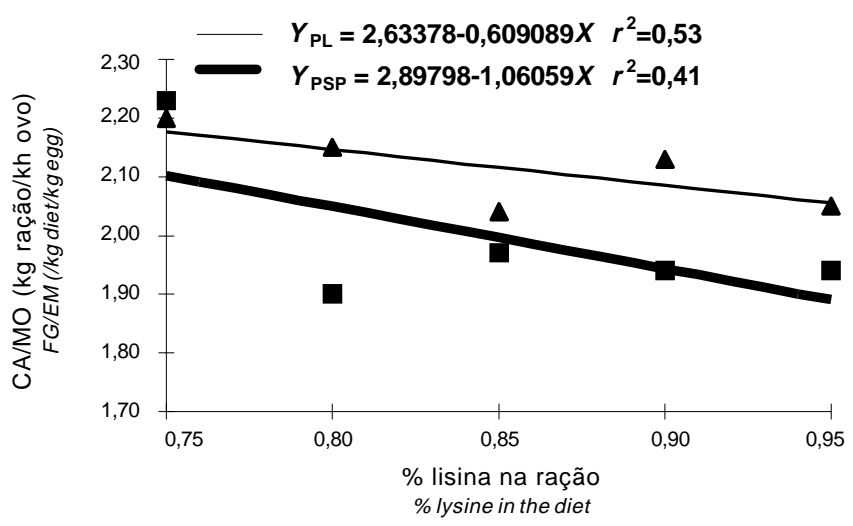

Figura 3 - Conversão alimentar por massa de ovos, em função do efeito dos níveis de lisina da ração de 0 a 6 semanas.

Figure 3 - Egg:mass ratio(kg diet/kg egg production), in function of dietary lysine level from 0 to 6 weeks. 
Rev. bras. zootec.

development. World's Poult. Sci. J., 42:259-267.

DOUGLAS, C.R., HARMS, R.H. 1982. The influence of low protein grower diets on spring housed pullets. Poult Sci., 61:1885-1890.

FISHER, C., GRIMINGER, G.A., SHAPIRO, R. 1960. Quantitating aspects of lysine deficiency and amino acid imbalance. J. Nutr., 71:213.

FLOCK, D.K. 1998. Genetic-economic aspects of feed efficiency in laying hens. World's Poult. Sci. J., 54:225-239.

FURLAN, R.L., MACARI, M. Mecanismos fisiológicos do empenamento das aves. In: SIMPÓSIO INTERNACIONAL SOBRE NUTRIÇÃO DE AVES, Campinas, SP. 1998. Anais... Campinas, SP: CBNA, 1998. p.29-48.

GOUS, R.M., GRIESSEL, M., MORRIS, T.R. 1987. Effect of dietary energy concentration on the response of laying hens to amino acids. Br. Poult. Sci., 28:427-436.

HOCKING, P.M., GILBERT, A.B., WALKER, M., WADDINGTON, D. 1987. Ovarian follicular structure of white leghorns fed as libitum and dwarf and normal broiler breeders fed ad libitum or restricted until point of lay. Brit. Poult. Sci., 28:493-506.

HOWLIDER, M.A.R., ROSE, S.P. 1987. Temperature and the growth of broilers. World's Poult. Sci. J., 43:228-237.

JOHNSON, R.J., CUMMING, R.B., FARRELL, D.J. 1985. Influence of food restriction during rearing on the body composition of layer-strain pullets and hens. Brit. Poult. Sci., 26:335-348.

KLAIN, G.J., VAUGHAN, D.A., VAUGHAN, L.N. 1962. Interrelationships of cold exposure and amino acid imbalance. J. Nutr., 78:359-364.

KLASING, K.C., BARNES, D.M. 1988. Decreased amino acid requirements of growing chicks due to immunologic stress. J. Nutr., 118:1158-1164.

KWAKKEL, R.P., KONING, F.L.S.M., VERSTEGEN, M.W.A., HOF, G. 1991. Effect of method and phase of nutrient restriction during rearing on productive performance of light hybrid pullets and hens. Brit. Poult. Sci., 32:747-761.

LEE, P.J.W., GULliVER, A.L., MORRIS, T.R. 1971. A quantitative analysis of the literature concerning the restricted feeding of growing pullets. Brit. Poult. Sci., 12:413-437.

MANUAL DE CRIAÇÃO E MANEJO - LOHMANN LSL. Granja Planalto-Lohmann. Uberlândia, MG. 1997. 23p.

MANUAL DA LINHAGEM ISA BROWN. Guía de manejo Ponedoras Isa Brown. 1996. 16p.

MORRIS, T.R., AL-AZZAWI, K., GOUS, R.M. et al. 1987. Effects of protein concentration on responses to dietary lysine by chicks. Brit. Poult. Sci., 28:185-195.

MORRIS, T.R., GOUS, R.M., FISHER, C. 1999. An analysis of the hypothesis that amino acid requirements for chicks should be stated as a proportion of dietary protein. World's Poult. Sci. J., 55:7-22.
NATIONAL RESEARCH COUNCIL - NRC. 1994. Nutrient requirement of poultry. 9.ed., Washington, D.C.: National Academic Press. 155p.

RANGEL-LUGO, M., SU, C.L., AUSTIC, R.E. 1994. Threonine requirement and threonine imbalance in broiler chicks. Poult. Sci., 73:670-681.

ROBBINS, K.R. 1987. Threonine requirement of the chick as affected by protein level and source. Poult. Sci., 66:15311534.

ROSTAGNO, H.S., SILVA, D.J., COSTA, P.M.A. et al. 1983. Composição de alimentos e exigências nutricionais de aves e suínos: tabelas brasileiras. Viçosa, MG: UFV. 61p.

ROSTAGNO, H.S., BARBARINO JR., P., BARBOZA, W. Exigências nutricionais das aves determinadas no Brasil. In: SIMPÓSIO INTERNACIONAL SOBRE EXIGÊNCIAS NUTRICIONAIS DE AVES E SUÍNOS, 1996, Viçosa, MG. Anais... Viçosa, MG: UFV, 1996. p.361-388.

SAKOMURA, N.K., ROSTAGNO, H.S., SILVA, M.A., et al. 1993. Efeito da temperatura sobre o consumo de ração e de energia metabolizável para poedeiras comerciais. $R$. Soc. Bras. Zootec., 22:715-722.

SCOTT, M.L. 1988. Dietary nutrient allowances for chickens, turkeys. Feedstuffs, 21:72-76.

SHALEV, B.A. 1995. Comparison of white and brown egg shell laying stocks. World's Poult. Sci. J., 51:7-16.

SUMMERS, J.D., LEESON, S, SPRATT, D. 1987. Rearing early maturing pullets. Poult. Sci., 66:1750-1757.

UNIVERSIDADE FEDERAL DE VIÇOSA - UFV. 1982. SAEG - Sistema para análise estatística e genética. Viçosa, MG: $59 \mathrm{p}$.

ZOLlitsCH, W., CAO, Z., PEGURI, A. et al. Nutrient requirements of laying hens. In: SIMPÓSIO INTERNACIONAL SOBRE EXIGÊNCIAS NUTRICIONAIS DE AVES E SUÍNOS, 1996, Viçosa, MG. Anais... Viçosa, MG, UFV, 1996. p.109-159.

WADDINGTON, D., HOCKING, P.M. 1993. Modification of intra-ovarian follicular destributions in broiler breeder hens by ad libitum or restricted feeding. Brit. Poult. Sci., 34:777-784.

WELLS, R.G. 1980. Pullet feeding systems during rearing in relation to subsequent laying performance. Recent Advances in Animal Nutrition, p.185-202.

Recebido em: 02/12/99

Aceito em: 26/04/00 